\title{
EVALUASI EFESIENSI REAKTOR UREA (R-201) PABRIK UREA 1A PT. PUPUK KALIMANTAN TIMUR
}

\author{
Kristinah Haryani $^{1)}$, Mohammad Razak Scesario ${ }^{2)}$, M Sugiarto ${ }^{3)}$, Suryanto ${ }^{4)}$ \\ ${ }^{1,2,3)}$ Departemen Teknik Kimia, Fakultas Teknik, Universitas Diponegoro Semarang \\ J1. Prof Soedharto - 50239 Semarang, Telp./Fax. 024-7460058 \\ 4) Jurusan Teknik Mesin Politeknik Negeri Semarang \\ Jl. Prof Soedharto - 50239 Semarang \\ Email: krisyani_83@yahoo.co.id
}

\begin{abstract}
Abstrak
Urea adalah senyawa organik yang tersusun dari unsur karbon, hidrogen, oksigen dan nitrogen dengan rumus $\mathrm{CON}_{2} \mathrm{H}_{4}$ atau $\left(\mathrm{NH}_{2}\right)_{2} \mathrm{CO}$. Pabrik Urea Kaltim-1A menggunakan proses Stamicarbon "total recycle $\mathrm{CO}_{2}$ stripping" dengan memanfaatkan Ammonia cair dan $\mathrm{CO}_{2}$ yang diproduksi oleh unit Ammonia Kaltim-1A. Unit sintesa ialah suatu unit yang penting dalam proses pembuatan urea. Dalam penelitian ini permasalahan yang diangkat ialah mengevaluasi efisiensi reaktor urea pada berbagai tingkatan level didalam reaktor dengan membandingkan hasil perhitungan teoritis dengan aktual yang ada di pabrik guna untuk melihat kondisi reaktor saat ini. Dari hasil pengamatan diperoleh bahwa semakin tinggi suhu reaktor maka konversi yang terbentuk semakin besar pula, konversi semakin besar seiring semakin tinggi posisi larutan di dalam reaktor, dan berdasarkan hasil simulasi didapat letak ketinggian indikator TI204, TI-203, TI-202, TI-201 beserta konversi $\mathrm{CO}_{2}$ nya.
\end{abstract}

Kata Kunci : "Evaluasi”, "Efisiensi”, "Reaktor urea”

\section{Pendahuluan}

Urea adalah senyawa organik yang tersusun dari unsur karbon, hidrogen, oksigen dan nitrogen dengan rumus $\mathrm{CON}_{2} \mathrm{H}_{4}$ atau $\left(\mathrm{NH}_{2}\right)_{2} \mathrm{CO}$. Proses pembentukan urea merupakan hasil reaksi antara ammonia $\left(\mathrm{NH}_{3}\right)$ dan karbon dioksida $\left(\mathrm{CO}_{2}\right)$. Pabrik Urea Kaltim-1A menggunakan proses Stamicarbon "total recycle $\mathrm{CO}_{2}$ stripping" dengan memanfaatkan Ammonia cair dan $\mathrm{CO}_{2}$ yang diproduksi oleh unit Ammonia Kaltim-1A.

Secara garis besar proses pembuatan urea terbagi menjadi beberapa unit penting yaitu, persiapan bahan baku, sintesa, resirkulasi, evaporasi, granulasi dan finishing. Pada pabrik urea Kaltim-1A sintesa urea dilakukan dengan menggunakan 4 alat utama yaitu HPCC (High Pressure Carbamat Condenser), Reactor, HP Stripper, dan HP Scrubber, 4 alat utama ini membentuk suatu resirkulasi yang dinamakan synthesis loop. Unit sintesa ialah suatu unit yang penting dalam proses pembuatan urea. Dalam tugas khusus ini permasalahan yang diangkat ialah mengevaluasi efisiensi reaktor urea pada berbagai tingkatan level didalam reaktor dengan membandingkan hasil perhitungan teoritis dengan aktual yang ada di pabrik guna untuk melihat kondisi reaktor saat ini.

Reaktor Sintesa urea adalah jantung terjadinya reaksi pembentukan urea di proses pabrik-1A. Campuran gas $\left(\mathrm{NH}_{3}, \mathrm{CO}_{2}\right)$ dan larutan (karbamat) dari HPCC akan mengalir menuju reaktor melalui 2 line yang berbeda, dengan temperatur berkisar $176^{\circ} \mathrm{C}$. Reaksi yang diharapkan terjadi pada reaktor adalah: $\mathrm{NH}_{2} \mathrm{COONH}_{4} \Leftrightarrow \mathrm{CO}\left(\mathrm{NH}_{2}\right)_{2}+\mathrm{H}_{2} \mathrm{O} \Delta \mathrm{H}=+3-$ $6 \mathrm{~kJ} / \mathrm{mol}$

Reaksi endotermik diatas disuplai kebutuhan panasnya oleh $20 \% \quad \mathrm{CO}_{2}$ dan $\mathrm{NH}_{3}$ yang mengeluarkan panas saat bereaksi menjadi karbamat. Selain reaksi diatas dapat pula terjadi reaksi lanjutan pembentukan biuret, sebagai berikut:

\section{$\mathrm{CO}\left(\mathrm{NH}_{2}\right)_{2} \Leftrightarrow \mathrm{NH}_{2} \mathrm{CONHCONH}_{2}+\mathrm{NH}_{3}$}

Agar biuret tidak terbentuk, aspek operasional yang perlu dihindari adalah temperatur operasi yang tinggi, waktu tinggal (residence time) yang lama, dan konsentrasi 
urea yang tinggi atau konsentrasi ammonia yang rendah.

Reaktor sintesis urea terdiri dari 11 buah sieve tray dengan jumlah lubang pada setiap tray berbeda-beda. Semakin ke atas jumlah lubang pada tray semakin sedikit. Hal tersebut bertujuan untuk meningkatkan kontak antara fasa gas dan cair dan memperoleh waktu tinggal yang diperlukan yaitu berkisar 1-1,5 jam. Urea yang terbentuk memiliki konsentrasi sekitar 38\% dengan nilai konversi gas $\mathrm{CO}_{2}$ sekitar $60 \%$. Hasil reaksi berupa larutan akan keluar melalui overflow pada bagian bottom reaktor dengan temperatur $183^{\circ} \mathrm{C}$ dengan kandungan berupa urea, air, karbamat, dan sisa ammonia untuk selanjutnya dikirim menuju HP Stripper (P2E201). Gas $\mathrm{NH}_{3}, \mathrm{CO}_{2}$ dan gas inert yang tidak bereaksi keluar reaktor melalui bagian atas untuk diproses di HP Scrubber (P2E203).

Variabel yang harus di perhatikan saat proses sintesa urea adalah :

- Rasio N/C mulai inlet HPCC sampai keluar reaktor berkisar 2,9-3,0

- Tekanan sintesa yang berkisar antara $143-145 \mathrm{~kg} / \mathrm{cm}^{2} \mathrm{G}$

- Temperatur inlet reaktor berkisar $170{ }^{\circ} \mathrm{C}$

- Temperatur outlet reaktor berkisar $182^{\circ} \mathrm{C}$

Pada kondisi tersebut di peroleh :

- Konversi $\mathrm{CO}_{2}$ menjadi urea dalam reaktor antara $59-60 \%$

- Efisiensi stripping di dalam stripper sekitar $80-85 \%$

(Team Start Up POPKA, 1998)

\section{Metode}

\subsection{Pengumpulan Data}

Dalam pengumpulan data terdapat dua jenis data yaitu data primer dan data sekunder. Data primer merupakan data yang diperoleh dari pengamatan dan pengukuran besaran operasi alat yang bersangkutan secara langsung di lapangan serta data spesifikasi rancangan alat yang dievaluasi. Data primer juga didapat dari data logsheet, dan hasil analisa lab unit Urea Pabrik-1A tanggal 31 Juli 2018. Data sekunder merupakan data yang diperoleh dari studi literatur umum maupun dari Unit Urea Pabrik-1A. Data-data sekunder yang diperoleh ialah :

1) Data Desain Process Flow Diagram maupun Process \& Instrumentation Diagram unit Sintesa Urea Pabrik-1A

2) Data desain neraca massa unit Sintesa Urea dan spesifikasi desain alat dari Engineering Datasheet dan juga Mechanical Catalog Urea Pabrik-1A

3) Berat molekul komponen

4) Enthalpy pembentukan senyawa

5) Densitas larutan pada setiap aliran proses

Dalam melakukan pengumpulan data hingga penyusunan studi kasus diberlakukan beberapa asumsi yang perlu diperhatikan seperti :

1) Simulasi Proses dilakukan pada basis system Steady-state/ keadaan tunak.

2) Rate Operasi Pabrik Urea-1A proporsional terhadap mass flow umpan ke unit sintesa.

3) Faktor transportasi fluida seperti friksi pipa, heat loss, fluid leakage dan factor faktor lainnya yang mungkin terjadi di lapangan diabaikan.

4) $\mathrm{CO}_{2}$ bebas di representasikan sebagai liquid dalam bentuk ammonia Carbamate

5) Tidak ada carbamate dan urea dalam bentuk gas.

6) Gas inert hanya didapat dari udara berupa $\mathrm{O}_{2}$ dan $\mathrm{N}_{2}$.

7) Pembentukan biuret diabaikan

\subsection{Langkah Penyelesaian Masalah}

Adapun langkah yang digunakan untuk menyelesaikan masalah :

1) Mempelajari proses sintesa urea pada Pabrik-1A 
2) Mengumpulkan data primer dan data sekunder

3) Membuat permodelan menggunakan Neraca Massa dan Neraca Panas berasal dari reaktor Urea (2-R-201)

4) Memulai simulasi Reaktor urea (2-R-201) menggunakan software pemrograman Matlab, data yang digunakan untuk simulasi proses didalam reaktor urea ialah data desain dari "buku petunjuk operasi pabrik urea unit-4 POPKA" Pabrik-1A.

5) Mengulangi simulasi dengan menggunakan data aktual yang didapat dari lapangan yang digunakan guna mengevaluasi kinerja Reaktor R-201 dengan membandingkan hasil yang didapat dari simulasi dengan menggunakan data desain dan data aktual.

6) Membahas hasil yang didapatkan.

\section{Hasil dan Pembahasan}

\subsection{Hubungan Suhu Terhadap Konversi Pada Proses Sintesa}

Di dalam reaktor urea terjadi reaksi pembetukan ammonium karbamat dan reaksi dehidrasi ammonium karbamat menjadi urea. Panas reaksi pembentukan karbamat dimanfaatkan untuk melakukan reaksi dehidrasi ammonium karbamat menjadi urea yang bersifat endotermis. Ada nya panas reaksi yang dihasilkan dari reaksi pembentukan karbamat yang bersifat eksotermis menyebabkan suhu didalam reaktor semakin tinggi. Semakin tingginya suhu didalam reaktor menyebabkan konversi dehidrasi karbamat menjadi urea semakin besar. Hal ini disebabkan karena sifat reaksi dehidrasi ammonium karbamat menjadi urea yang bersifat endotermis, sehingga bila suhu dinaikkan maka kesetimbangan bergeser kearah kanan (produk). Sebaliknya, pada reaksi pembentukan ammonium karbamat bersifat eksotermis dimana semakin tinggi suhu maka kesetimbangan bergeser kearah kiri (reaktan). Namun panas yang dikeluarkan dimanfaatkan oleh reaksi dehidrasi urea sehingga konversi $\mathrm{CO}_{2}$ menjadi ammonium karbamat naik. Hubungan konversi dengan suhu ini dapat dilihat pada gambar 1 .

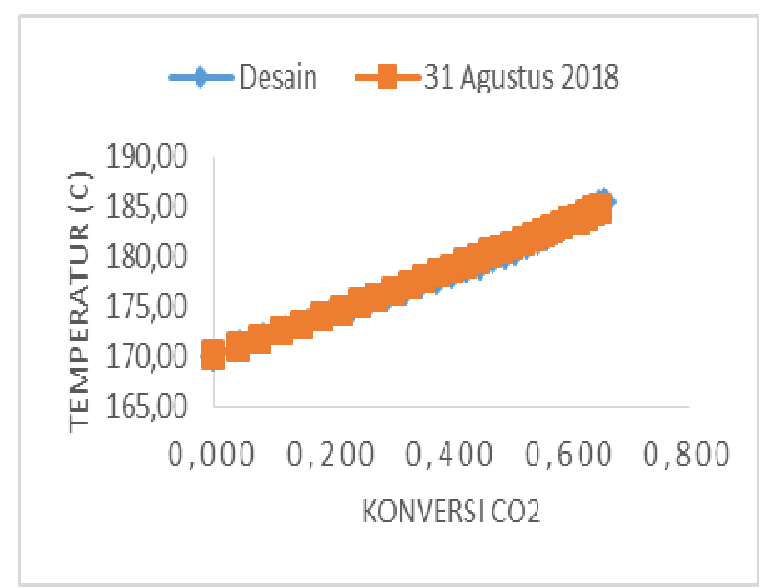

Gambar 1. Hubungan Suhu Reaktor dengan Konversi $\mathrm{CO}_{2}$

Pada hasil run simulasi terdapat sedikit penyimpangan hasil yakni konversi menjadi urea desain sebesar 59,5\% lebih besar dibandingkan dengan konversi aktual pada tanggal 31 Juli 2018 sebesar 58,9\%. Hal ini bisa dikarenakan banyaknya jumlah air yang masuk ke dalam reaktor. Semakin banyak karbamat yang terkonversi menjadi urea, maka semakin banyak air yang terbentuk, sehingga kesetimbangan akan bergeser ke arah kiri (ke arah reaktan) hingga suatu kondisi dimana jumlah air lebih banyak daripada jumlah karbamat. Selain itu, penyimpangan bisa terjadi diakibatkan pengambilan data dari referensi yang berbeda. Hal ini berkaitan dengan nilai kapasitas panas $(\mathrm{Cp})$ yang digunakan pada simulasi perhitungan Matlab. Apabila digunakan nilai $\mathrm{Cp}$ yang berbeda, maka akan berbeda pula besarnya nilai konversi yang didapat dari simulasi (Perry, 1986). 


\subsection{Hubungan Tinggi Terhadap Konversi Pada Proses Sintesa}

Berdasarkan gambar 2 dapat dilihat bahwa ketika tinggi reaktor semakin meningkat maka konversi akan semakin tinggi. Hal ini dikarenakan semakin tinggi reaktor maka waktu tinggal didalam reaktor semakin lama. Hal ini menyebabkan proses pembentukan karbamat dan proses dehidrasi karbamat menjadi urea semakin lama sehingga dapat menghasilkan produk yang lebih banyak. Berdasarkan rumus,

$d X_{A 2}=\frac{(-r o) \cdot A+\left(F_{A Q}-F_{A Q} \cdot X_{A 2}\right) \frac{d X_{A 1}}{d z}}{\left(F_{c o}+F_{A Q} \cdot X_{A 1}\right)} \cdot d z$

Dari persamaan diatas dapat diketahui bahwa tinggi berbanding lurus dengan konversi dehidrasi karbamat menjadi urea sehingga semakin tinggi reaktor maka semakin besar pula konversi yang didapat (Levenspiel, 1972).

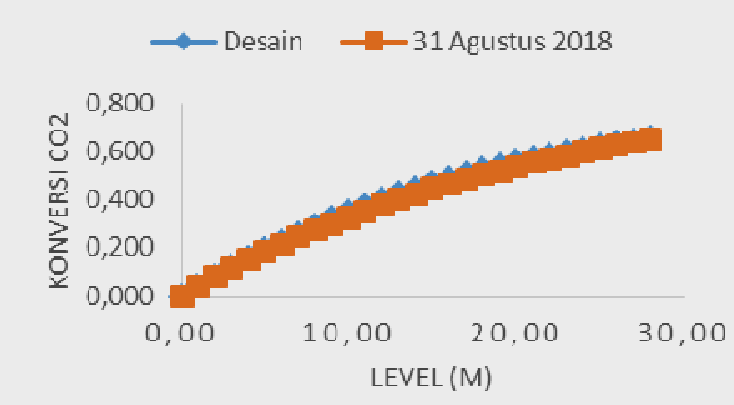

Gambar 2. Hubungan Tinggi Reaktor dan Konversi.

Namun semakin tinggi reaktor dapat menyebabkan pembentukan produk samping biuret. Hal ini dikarenakan bila reaktor semakin tinggi maka waktu tinggal didalamnya semakin lama, sehingga dapat menyebabkan reaksi lanjutan urea menjadi biuret. Biuret merupakan racun bagi tanaman sehingga keberadaannya sangat diusahakan seminimal mungkin. Oleh karena itu pada reaktor sintesa urea, waktu tinggal didalam reaktor hanya 1 jam dan level reaktor dijaga sebesar $60-70 \%$ tinggi reaktor.

\subsection{Konversi pada setiap indikator level}

Berdasarkan hasil simulasi dengan menggunakan program Matlab yang dapat dilihat pada Tabel 1. didapatkan data sebagai berikut.

Tabel 1. Hasil simulasi menggunakan data aktual tanggal 31 Juli 2018

\begin{tabular}{ccccc}
\hline Nama Alat & $\begin{array}{c}\text { Tinggi } \\
(\mathbf{m}) \\
\text { Desain }\end{array}$ & $\begin{array}{c}\text { Suhu Data } \\
\text { Aktual }\left({ }^{\circ} \mathbf{C}\right)\end{array}$ & $\begin{array}{c}\text { Konversi } \\
\mathbf{C O}_{2} \\
\text { Simulasi } \\
\text { Data aktual } \\
\left({ }^{\circ} \mathbf{C}\right)\end{array}$ & $\begin{array}{c}\text { Konversi } \\
\mathbf{C O}_{2} \text { Simulasi } \\
\text { Data Desain } \\
\left({ }^{\circ} \mathbf{C}\right)\end{array}$ \\
\hline TI-204 & 2,7 & 172,63 & 10,4 & 11,03 \\
TI-203 & 10,5 & 176,73 & 34,05 & 36,35 \\
TI-202 & 18,3 & 181,26 & 50,74 & 53,31 \\
TI-201 & 26,1 & 181,71 & 62,6 & 63,9 \\
\hline
\end{tabular}

Berdasarkan tabel 1 dapat dilihat bahwa konversi $\mathrm{CO}_{2}$ desain dan actual pada suhu yang sama memiliki perbedaan. Hal ini disebabkan karena nilai rasio N/C desain lebih besar daripada rasio N/C actual yang hanya 3,0. Semakin besar nilai rasio N/C maka konversi $\mathrm{CO}_{2}$ semakin besar, sehingga sesuai dengan Azaz Le Chatelier dimana penambahan konsentrasi pada suatu komponen dalam reaksi kesetimbangan akan menggeser kesetimbangan ke arah yang berlawanan (Zhang, 2001).

Selain itu pada tabel 1 juga dapat dilihat bahwa suhu pada indikator temperatur memiliki perbedaan antara aktual dan hasil dari simulasi . Hal ini disebabkan oleh ada nya perbedaan flowrate input desain dan aktual reaktor sehingga mempengaruhi perhitungan. Selain itu, nilai kapasitas panas (Cp) yang digunakan pada simulasi perhitungan Matlab juga berpengaruh. Apabila digunakan nilai $\mathrm{Cp}$ yang berbeda, maka akan berbeda pula besarnya nilai yang didapat dari simulasi. Keterbatasan software Matlab yang merupakan pendekatan juga mempengaruhi hasil terutama pada ketinggian diatas $23 \mathrm{~m}$ (Perry, 1986). Seharusnya pada kondisi diatas tray terakhir (23m) sudah tidak terjadi konversi, namun 
karena pada fungsi matlab ini berbanding lurus antara tinggi dan konversi sehingga dari hasil simulasi masih terjadi kenaikan konversi.

\section{Kesimpulan}

Berdasarkan hasil perhitungan, hasil simulasi, serta data-data yang telah dikumpulkan baik data primer ataupun data sekunder maka dapat disimpulkan sebagai berikut. Suhu di dalam reaktor akan mempengaruhi konversi didalam reaktor. Semakin tinggi suhu reaktor maka konversi yang terbentuk semakin besar pula. Akan tetapi pada suhu yang terlalu tinggi dapat menyebabkan pembentukan biuret, sehingga perbedaan suhu input dan output dijaga sekitar $10-11^{\circ} \mathrm{C}$ untuk mendapatkan konversi maksimum, konversi semakin besar seiring semakin tinggi posisi larutan di dalam reaktor, hal ini disebabkan semakin tinggi posisi larutan maka semakin lama pula waktu tinggal didalam reaktor sehingga konversi semakin besar, dan berdasarkan hasil simulasi didapat letak ketinggian indikator TI-204， TI-203， TI-202， TI-201 beserta konversi $\mathrm{CO}_{2}$ nya.

\section{Daftar Pustaka}

- Levenspiel, O., 1972, "Chemical Reaction Engineering”, 2nd ed, John Wiley and Sons Inc, Singapore

- Perry, R. H., Green, D. W., and Maloney, J. O., 1986, "Perry's Chemical EngineersHandbook", 6th ed., McGraw Hill-Book Co, Singapore.

- Team Start Up POPKA. 1998. "Buku Petunjuk Operasi Pabrik Urea Unit4 POPKA". Bontang : PT. Pupuk Kalimantan Timur.

- Treybal, E. R., 1981, "Mass-Transfer Operations", 3rd ed., McGraw HillBook Co, Singapore.

- Zhang, X.P., Yao, P.J., Wu, D., and Yuan, Y., 2001, "Simulation of Urea Reactor of Industrial Process", China : Dalian University of Technology. 